\title{
Molecular Diagnosis of Friedreich Ataxia Using Analysis of GAA Repeats and FXN Gene Exons in Population from Western India
}

\author{
Pravin D. Potdar and Aarthy Raghu \\ Department of Molecular Medicine \& Biology, Jaslok Hospital \& Research Centre, 15 Dr. G. Deshmukh Marg, \\ Mumbai 400026, Maharashtra, India \\ Correspondence should be addressed to Pravin D. Potdar; ppotdar@jaslokhospital.net
}

Received 15 July 2013; Accepted 21 August 2013

Academic Editors: Y. Kuroiwa, F. Saccà, and C. E. Wang

Copyright (C) 2013 P. D. Potdar and A. Raghu. This is an open access article distributed under the Creative Commons Attribution License, which permits unrestricted use, distribution, and reproduction in any medium, provided the original work is properly cited.

\begin{abstract}
The diagnosis of Friedreich ataxia is based on the clinical symptoms and GAA repeats expansions. In our experience, checking FXN gene exons for mutations along with GAA repeat analysis may give better clue for its diagnosis. In the present study, total 49 suspected Friedreich ataxia patients were analyzed for GAA repeat expansion. Eleven patients have normal number of GAA repeats, thereby termed as FRDA negative patients. Thirty-eight patients showed no amplification using GAA repeat analysis. Since no conclusion was possible based on these results, these patients were designated as uninformative. We have analyzed 5 exons of the FXN gene in FRDA negative and uninformative patients to check for possible mutations. It was observed that there were no mutations found in any of FRDA negative and most uninformative patients. We further used long range PCR to check for deletion of exon 5a. It was found that 18 patients showed expression for exon 5a PCR but none in long range PCR. Five patients showed no expression for exon 5a PCR as well as long range PCR indicating that these 5 patients may be positive FRDA patients. These findings need to be correlated with clinical history of these patients for confirmation.
\end{abstract}

\section{Introduction}

Friedreich ataxia (FRDA) is an autosomal recessively inherited neurodegenerative disease, caused due to expansion of the intronic GAA trinucleotide repeats or mutations in the FXN gene on chromosome 9q13 [1,2]. The FXN gene consists of seven exons-1, 2, 3, 4, 5a, 5b, and 6. Frataxin, a highly conserved 210 amino acid protein with functions in ironsulfur cluster biosynthesis, is produced by expression of exons 1-5a [1-6]. The gene FXN contains a GAA trinucleotide repeat in the first intron. The size range of the repeat is between 6 and 34 repeats in the wild-type gene $[1,7]$. An expansion of the repeat in disease conditions increases the repeat size to $66-1700$ or more repeats $[1,7]$. It affects the expression of the gene, resulting in the reduced levels of frataxin mRNA and protein $[3,8]$. Formation of sticky DNA, DNA-RNA hybrid, and epigenetic changes are the proposed mechanisms for disruption of FXN gene expression [9-11].

Most cases of FRDA are homozygous having expansion of the GAA trinucleotide repeat in the first intron of the FXN gene, whereas few cases can be heterozygous, in which there is GAA expansion in one allele and point mutation or deletion in the other allele of FXN gene [1,2]. The onset of FRDA is usually before 25 years of age $[1,12]$. However, the diseaseonset after 25 years of age is known as late onset Friedreich ataxia (LOFA) [1]. The clinical features of FRDA include progressive gait and limb ataxia, scoliosis, proprioception, cardiomyopathy, diabetes mellitus, and foot deformity $[1,12]$.

Clinical features can be used as primary criteria for the diagnosis of FRDA [12]. However, since many neurological disorders share similar symptoms, it is necessary to use molecular diagnostic tests to confirm the diagnosis. Many diagnostic techniques for FRDA are available based on analysis of DNA [2,13-19] as well as measurement of frataxin mRNA [20] and protein levels [21-24]. Also, many mutations have been identified in the FXN gene [2, 14, 25-29]. These mutations include point mutations $[2,14,25,26]$, deletion of few nucleotides [27], deletion-insertion mutations [28], and deletion of complete exons $[14,24]$. Complete deletion of 
TABLE 1: This table describes the clinical features of some suspected Friedreich ataxia patients, whose samples were analyzed in this study.

\begin{tabular}{lcccc}
\hline Sr. number & Patient & Age & Sex & Clinical symptoms \\
\hline 1 & Uninformative & 18 & $\mathrm{~F}$ & Unsteadiness of gait, slurring of speech since 6 years \\
2 & FRDA negative & 23 & $\mathrm{~F}$ & Imbalance while walking \\
3 & FRDA negative & 12 & $\mathrm{M}$ & Imbalance while walking \\
4 & FRDA negative & 17 & $\mathrm{M}$ & Imbalance while walking \\
5 & Uninformative & 32 & $\mathrm{M}$ & Wide-based gait, positive cerebellar signs \\
6 & FRDA negative & 31 & $\mathrm{~F}$ & Imbalance while walking \\
7 & Uninformative & 16 & $\mathrm{~F}$ & Imbalance while walking \\
8 & Uninformative & 11 & $\mathrm{M}$ & Imbalance while walking \\
9 & FRDA negative & 52 & $\mathrm{M}$ & Imbalance while walking \\
10 & Uninformative & 20 & $\mathrm{M}$ & Imbalance while walking \\
11 & FRDA negative & 12 & $\mathrm{~F}$ & Mild to severe cerebellar ataxia \\
\hline
\end{tabular}

the FXN gene has also been found to occur in FRDA [29]. It is therefore important to check for mutations in all the exons of the FXN gene along with GAA repeat analysis.

\section{Materials and Methods}

2.1. Samples. Blood samples were collected from normal individuals, and patients were referred to Jaslok Hospital and Research Centre, Mumbai, India, and used for further analysis as per the guidelines of Ethical Committee of Jaslok Hospital and Research Centre. DNA was extracted from the blood samples by using Qiagen (Qiagen, Hilden, Gmbh) Q1Aamp DNA extraction kit as per their established protocol. The clinical features of some of the suspected patients are described in Table 1.

2.2. Molecular Analysis. Molecular analyses of DNA samples were performed using PCR followed by agarose electrophoresis. DNA sequencing was used for further analysis of FXN gene exons.

2.2.1. Analysis of Expanded GAA Repeats. GAA repeat analysis was performed for 58 samples including 9 normal individuals and 49 patients. Analyses for expanded GAA repeats were performed using PCR using the following primer pair described by Campuzano et al. [2]: forward: $5^{\prime}$-GGAGGGAACCGTCTGGGCAAAGG-3'; reverse: $5^{\prime}$ CAATCCAGGACAGTCAGGGCTTT-3' . Conditions used for FRDA primers were as follows: 20 cycles of $94^{\circ} \mathrm{C}$ for 20 seconds, $68^{\circ} \mathrm{C}$ for $2 \mathrm{~min} 30$ seconds, followed by 17 cycles in which the $68^{\circ} \mathrm{C}$ step was increased by 15 seconds per cycle, followed by a final extension of $72^{\circ} \mathrm{C}$ for $7 \mathrm{~min}$. The PCR products obtained were analysed by electrophoresis, on a $0.8 \%$ agarose gel stained with ethidium bromide.

Patients were classified as "FRDA negative" and "uninformative" based on results obtained from GAA repeat expansion analysis. 11-patient samples in which GAA repeats were detected to be normal were classified as "FRDA negative" while 38 patients for whom no results were obtained were classified as "uninformative."
2.2.2. Analysis of Exons of FXN Gene. Exons of the FXN gene were amplified in using primers described by Zühlke et al. [14]. The following PCR conditions were used for analysis of FXN gene exon 1: $95^{\circ} \mathrm{C}$ for $5 \mathrm{~min}$, which was followed by 35 cycles of $94^{\circ} \mathrm{C}$ for 30 seconds, and $72^{\circ} \mathrm{C}$ for $1 \mathrm{~min}, 72^{\circ} \mathrm{C}$ for 30 seconds, followed by $72^{\circ} \mathrm{C}$ for $10 \mathrm{~min}$. PCR conditions for analysis of FXN gene exons 2, 3, 4, and 5a were as follows: $94^{\circ} \mathrm{C}$ for $4 \mathrm{~min}$, followed by 35 cycles of $94^{\circ} \mathrm{C}$ for 30 seconds, $65^{\circ} \mathrm{C}$ for 30 seconds, $72^{\circ} \mathrm{C}$ for 45 seconds, followed by and $72^{\circ} \mathrm{C}$ for $10 \mathrm{~min}$. The PCR products obtained from exon PCR were analysed by electrophoresis on a $2 \%$ agarose gel.

Long PCR was used for analysing a segment of the FXN gene consisting of a part of intron 4 and part of exon $5 \mathrm{a}$. The primers used in this PCR were described by Zühlke et al. [14]. PCR conditions for analysis of FXN gene long PCR were as follows: $94^{\circ} \mathrm{C}$ for $5 \mathrm{~min}$, followed by 10 cycles of $94^{\circ} \mathrm{C}$ for 10 seconds, $63^{\circ} \mathrm{C}$ for 30 seconds, and $68^{\circ} \mathrm{C}$ for $8 \mathrm{~min}$, followed by 20 cycles in which the $68^{\circ} \mathrm{C}$ step was increased by 20 seconds per cycle followed by $68^{\circ} \mathrm{C}$ for $10 \mathrm{~min}$. The PCR products obtained from long PCR for exon 5 a deletion were analysed by electrophoresis, on a $0.8 \%$ agarose gel stained with ethidium bromide.

2.2.3. Sequencing. The products obtained by amplification of exons were further analysed by DNA sequencing on 3100 Genetic Analyzer by Applied Biosystems.

The sequences obtained by sequencing were compared with FXN gene mRNA cds sequence (Accession ID: U3747) which was numbered from 1 starting with A of ATG start codon from NCBI database. This comparison was performed using BioEdit Sequence Alignment Editor Software.

\section{Results}

3.1. GAA Repeat Analysis. The expected amplicon size from GAA repeat PCR is about $1.3 \mathrm{~kb}$ in normal individuals. The clinically suspected patients were expected to give amplicon size either similar to normal individuals, indicating normal GAA repeats, or larger than normal size, indicating presence of expanded GAA repeats [2]. Figure 1 shows the results obtained from GAA repeat analysis. Nine normal individuals 


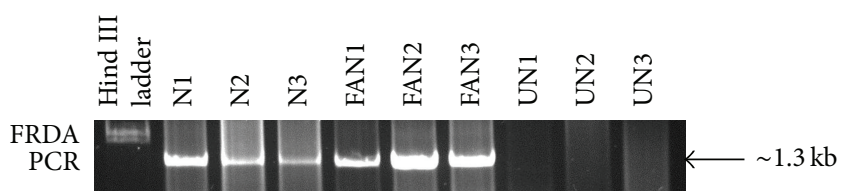

FIGURE 1: Shows results obtained from PCR for detection of expanded GAA repeats. Lanes N1, N2, and N3 represent normal patient's samples. Lanes FAN1, FAN2, and FAN3 represent FRDA negative patients and Lanes UN1, UN2, and UN3 represent uninformative patients showing no band.

and 11 clinically suspected cases of FRDA gave PCR products of expected size of $1.3 \mathrm{~kb}$ indicating that these patients could be negative for FRDA. Hence, these patients were termed as "FRDA negative" patients, whereas other 38 patients did not giveany amplification in GAA repeat analysis as shown in Figure 1. Therefore it was very difficult to mark these patients as positive or negative for FRDA. Hence, these patients were termed as "uninformative" patients.

3.2. PCR Analysis of Exons of FXN Gene. Results from GAA repeat analysis are not sufficient to determine whether uninformative patients were positive for FRDA. Therefore, we decided to analyze exons of the FXN gene in the patients using primers described by Zühlke et al. [14]. It was observed that all exons were amplified in all normal individuals and all FRDA negative patients giving expected product sizes as shown in Figures 2(a) and 2(b). However, in case of uninformative FRDA patients UN2 and UN3 \& UN5 did not give amplification in exon 4 and exon 1, respectively (Figure 2(c)). The amplified exons were further analyzed by DNA sequencing in order to check for presence of mutations.

3.3. Sequencing of FXN Gene Exons. We further analyzed the 5 FXN exons by DNA sequencing. We observed that there were no mutations found in normal individuals, all FRDA negative patients, and most of the uninformative patients. However, we found two novel mutations, that is, A226C and Ins246T in FXN exon 2 in one of the uninformative patients. The mutation $\mathrm{A} 226 \mathrm{C}$ results in a change of the amino acid methionine to leucine at position 76 (M76L), while the mutation Ins246T results in a frame shift mutation in the frataxin protein leading to termination of protein at position 92. The sites of mutations are highlighted in Figure 3 along with the corresponding electropherogram as shown in Figure 4. Therefore, this uninformative patient may be positive for FRDA.

3.4. Long PCR Analysis for Exon 5a. We further analyzed FXN exon 5a using primers for long range PCR, described by Zühlke et al. These primers gave a PCR product of $3983 \mathrm{~kb}$ including coding region of exon $5 \mathrm{a}$ and a part of intron 4 [14]. In our study, it was observed that all normal, FRDA negative individuals, and 13 uninformative patients gave the expected PCR product size of $\sim 4 \mathrm{~kb}$ as represented in Figure 5. However, 23 uninformative patients did not give any results in long range PCR. It was further observed that 18 of these 23 uninformative patients gave positive expression for coding region of FXN 5a gene. However, 5 uninformative patients were negative for FXN 5a long range PCR as well as coding region of FXN 5a indicating that these 5 patients may be FRDA positive patients. These patients should be correlated with their clinical history to confirm the status of FRDA in these uninformative patients.

\section{Discussion}

Extensive research has been carried out for understanding and diagnosis of Friedreich ataxia. Homozygous expansion of GAA repeats is the cause of $98 \%$ of FRDA cases [2]. Therefore, the presence of expanded GAA repeats in first intron of the FXN gene is used as basis for molecular diagnosis of FRDA in most of the cases. Many techniques have been explored for estimating GAA repeat size [2,13-19]. Occurrence of FRDA has been reported to be less frequent in Indian population [30]. In our research, we found that many patients showed no expansion of GAA repeats, and, hence, they may be called normal. Therefore, these patients were termed as "FRDA negative" patients. The remaining 38 patients studied in our lab did not give any amplification of GAA repeats as shown in Figure 1, and, hence, it was difficult to conclude the disease status of these patients. Therefore, these patients were termed as "uninformative patients." This situation has not been reported elsewhere.

There is a need of an additional test to determine the status of uninformative patients. Hence, we decided to analyze five exons of the FXN gene for presence of possible mutations. Two percent of FRDA cases are heterozygous for a mutation in the FXN gene exons [2]. Various types of mutations have been described, that is, point mutations, deletion of exons, and even complete deletion of the FXN gene in heterozygous patients [2, 14, 20-29]. In our analysis, we found that the exons of the FXN gene were normal in all FRDA negative patients and most of the uninformative patients. However, in one uninformative patient, two novel point mutations were observed in exon 2. Hence, this patient may be positive for FRDA.

We further analyzed exon 5a using long range PCR described by Zühlke et al. [14]. Zühlke et al. identified a heterozygous deletion of $2776 \mathrm{bp}$ including exon $5 \mathrm{a}$ using this method [14]. We observed that in long range PCR studies all FRDA negative and 13 out of 38 uninformative patients showed expression of $\sim 4 \mathrm{~kb}$ band indicating that all these patients were normal. However, remaining 23 uninformative patients showed no expression of exon $5 \mathrm{a}$ in long range PCR. This may be due to deletion or mutations in the intron 4 or exon 5 a region. It shows that there is a need of examining exon 5a in long range PCR for confirmation of uninformative patient as FRDA positive patient. Overall, this suggests that all of these 23 patients may be FRDA patients and this needs to be confirmed by correlation with their clinical symptoms.

\section{Conclusions}

Friedreich ataxia is an autosomal recessive neurodegenerative disorder that occurs commonly due to expansion of the GAA 


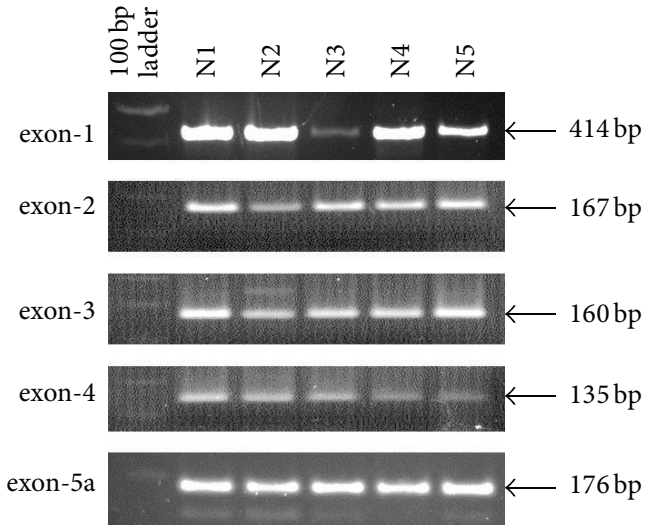

(a)

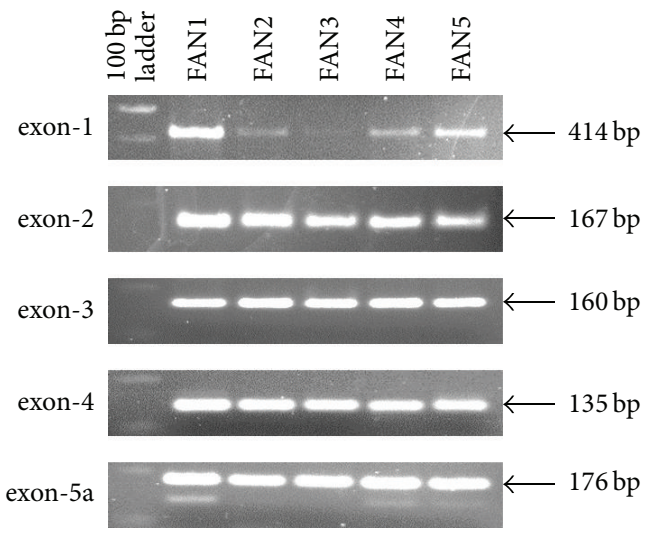

(b)

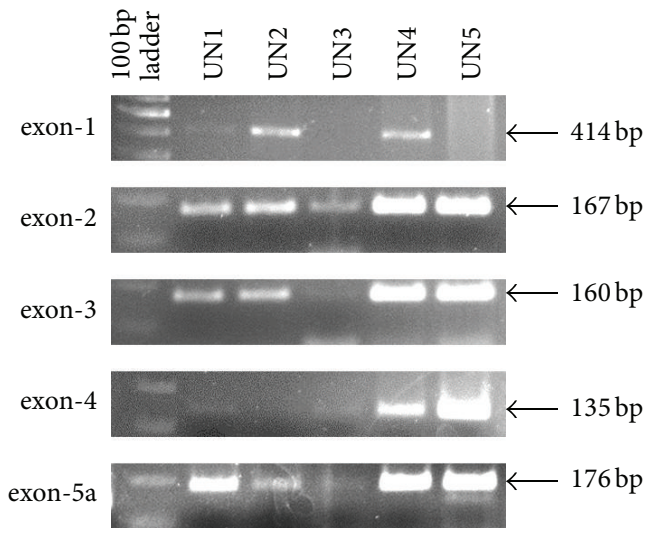

(c)

FIGURE 2: Shows exon PCR results for (a) normal samples represented by N1-N5, (b) FRDA negative samples represented by FAN1-FAN5, and (c) uninformative samples represented by UN1-UN5.

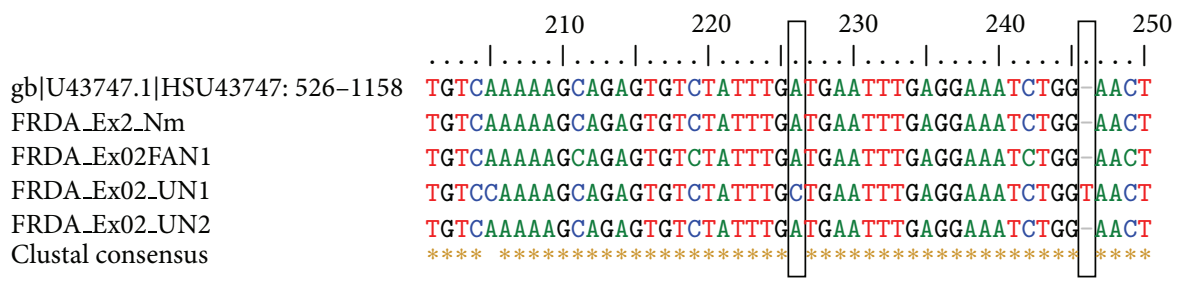

FIgURE 3: Shows BioEdit analysis of exon 2 of the FXN gene in normal individual, FRDA negative patient and one uninformative patient, which showed mutation at A226C and Ins246T. The sites of mutation in exon 2 have been highlighted by boxes.

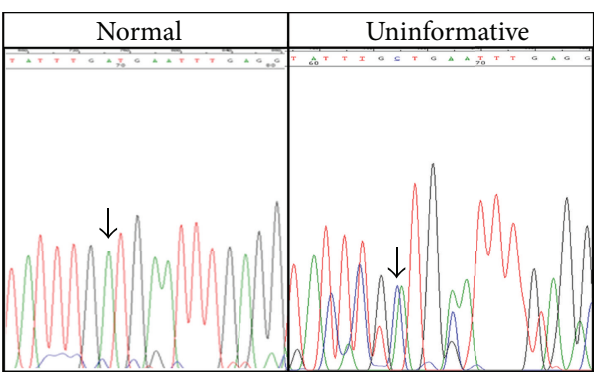

(a)

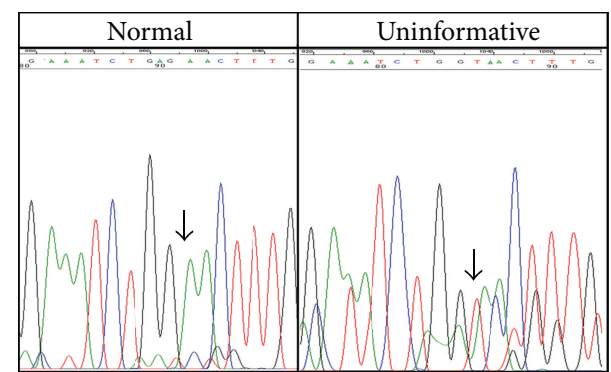

(b)

FIGURE 4: Shows electropherograms for 2 novel mutations (A226C and Ins246T) seen in one of the FRDA uninformative patient. The mutation sites are indicated by arrows. 


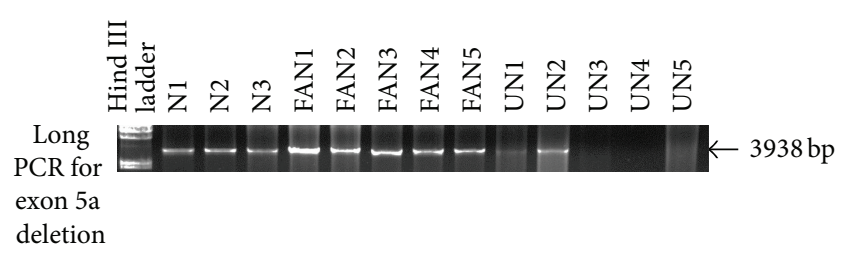

FIgURe 5: Shows results of long PCR for exon 5a analysis in normal individuals represented by Lanes N1-N3. FRDA negative patients are represented by Lanes FAN1-FAN5, and uninformative patients are represented by Lanes UN1-UN5.

trinucleotide repeats in first intron of FXN gene. Molecular diagnostic tests for FRDA are mainly based on detection of the GAA repeats. However, we found in our study of the West Indian patients that an additional test may be required to diagnose FRDA in cases which may give negative result for GAA repeat analysis. This may be due to heterogeneity in FXN gene. We, therefore, studied additional techniques such as mutation analysis in five exons of the FXN gene and exon $5 \mathrm{a}$ in long PCR to confirm these patients for FRDA. We found that there was no expression of exon 5a in long range PCR, which clearly confirmed the diagnosis of FRDA. Therefore, exon $5 \mathrm{a}$ in long range PCR is an essential test for FRDA in western Indian population. This study, thus, highlights the significance of examining FXN gene exons by mutation analysis and exon 5a in long range PCR and correlating the results with the clinical symptoms for a conclusive diagnosis of FRDA in patients from western India.

\section{Conflict of Interests}

The authors declare no conflict of interests.

\section{Acknowledgments}

The authors are thankful to the Management of Jaslok Hospital and Research Center, Mumbai, India, for providing the facilities for research on FRDA. The authors are also thankful to the staff of Department of Molecular Medicine and Biology at Jaslok Hospital \& Research Centre for their help in data collection and technical support during this study.

\section{References}

[1] M. B. Delatycki, R. Williamson, and S. M. Forrest, "Friedreich ataxia: an overview," Journal of Medical Genetics, vol. 37, no. 1, pp. 1-8, 2000.

[2] V. Campuzano, L. Montermini, M. D. Moltò et al., "Friedreich's ataxia: autosomal recessive disease caused by an intronic GAA triplet repeat expansion," Science, vol. 271, no. 5254, pp. 14231427, 1996.

[3] V. Campuzano, L. Montermini, Y. Lutz et al., "Frataxin is reduced in Friedreich ataxia patients and is associated with mitochondrial membranes," Human Molecular Genetics, vol. 6, no. 11, pp. 1771-1780, 1997.

[4] D.-P. Sirano, R. Shigeta, Y.-I. Chi, M. Ristow, and S. E. Shoelson, "Crystal structure of human frataxin," Journal of Biological Chemistry, vol. 275, no. 40, pp. 30753-30756, 2000.
[5] E. A. Roman, S. E. Faraj, M. Gallo, A. G. Salvay, D. U. Ferreiro, and J. Santos, "Protein stability and dynamics modulation: the case of human frataxin," PLoS ONE, vol. 7, article e45743, 2012.

[6] S. Schmucker, A. Martelli, F. Colin et al., "Mammalian frataxin: an essential function for cellular viability through an interaction with a preformed ISCU/NFS1/ISD11 iron-sulfur assembly complex," PLoS ONE, vol. 6, no. 1, article e16199, 2011.

[7] N. Sakamoto, K. Ohshima, L. Montermini, M. Pandolfo, and R. D. Wells, "Sticky DNA, a self-associated complex formed at long GAA.TTC repeats in intron 1 of the frataxin gene, inhibits transcription," Journal of Biological Chemistry, vol. 276, no. 29, pp. 27171-27177, 2001.

[8] K. Ohshima, L. Montermini, R. D. Wells, and M. Pandolfo, "Inhibitory effects of expanded GAA.TTC triplet repeats from intron I of the Friedreich ataxia gene on transcription and replication in vivo," Journal of Biological Chemistry, vol. 273, no. 23, pp. 14588-14595, 1998.

[9] S. I. Bidichandani, T. Ashizawa, and P. I. Patel, "The GAA triplet-repeat expansion in Friedreich ataxia interferes with transcription and may be associated with an unusual DNA structure," American Journal of Human Genetics, vol. 62, no. 1, pp. 111-121, 1998.

[10] E. Grabczyk, M. Mancuso, and M. C. Sammarco, "A persistent RNA.DNA hybrid formed by transcription of the Friedreich ataxia triplet repeat in live bacteria, and by T7 RNAP in vitro," Nucleic Acids Research, vol. 35, no. 16, pp. 5351-5359, 2007.

[11] R. D. Wells, "DNA triplexes and Friedreich ataxia," FASEB Journal, vol. 22, no. 6, pp. 1625-1634, 2008.

[12] A. E. Harding, "Friedreich's ataxia: a clinical and genetic study of 90 families with an analysis of early diagnostic criteria and intrafamilial clustering of clinical features," Brain, vol. 104, no. 3, pp. 589-620, 1981.

[13] S. Kocheva, S. Trivodalieva, S. Vlaski-Jekic, M. Kuturec, and G. D. Efremov, "Molecular analysis of Friedreich's ataxia in Macedonian patients," Balkan Journal of Medical Genetics, vol. 11, no. 1, pp. 61-64, 2008.

[14] C. H. Zühlke, A. Dalski, M. Habeck et al., "Extension of the mutation spectrum in Friedreich's ataxia: detection of an exon deletion and novel missense mutations," European Journal of Human Genetics, vol. 12, no. 11, pp. 979-982, 2004.

[15] P. J. Lamont, M. B. Davis, and N. W. Wood, "Identification and sizing of the GAA trinucleotide repeat expansion of Friedreich's ataxia in 56 patients. Clinical and genetic correlates," Brain, vol. 120, no. 4, pp. 673-680, 1997.

[16] A. Filla, G. De Michele, F. Cavalcanti et al., "The relationship between trinucleotide (GAA) repeat length and clinical features in Friedreich ataxia," American Journal of Human Genetics, vol. 59, no. 3, pp. 554-560, 1996.

[17] C. Cagnoli, C. Michielotto, T. Matsuura et al., "Detection of large pathogenic expansions in FRDA1, SCA10, and SCA12 genes using a simple fluorescent repeat-primed PCR assay," Journal of Molecular Diagnostics, vol. 6, no. 2, pp. 96-100, 2004.

[18] P. Ciotti, E. Di Maria, E. Bellone, F. Ajmar, and P. Mandich, "Triplet repeat primed PCR (TP PCR) in molecular diagnostic testing for Friedreich ataxia," Journal of Molecular Diagnostics, vol. 6, no. 4, pp. 285-289, 2004.

[19] A. Dürr, M. Cossee, Y. Agid et al., "Clinical and genetic abnormalities in patients with Friedreich's ataxia," The New England Journal of Medicine, vol. 335, no. 16, pp. 1169-1175, 1996.

[20] L. Pianese, M. Turano, M. S. Lo Casale et al., "Real time PCR quantification of frataxin mRNA in the peripheral blood leucocytes of Friedreich ataxia patients and carriers," Journal of Neurology, Neurosurgery and Psychiatry, vol. 75, no. 7, pp. 10611063, 2004. 
[21] J. H. Willis, G. Isaya, O. Gakh, R. A. Capaldi, and M. F. Marusich, "Lateral-flow immunoassay for the frataxin protein in Friedreich's ataxia patients and carriers," Molecular Genetics and Metabolism, vol. 94, no. 4, pp. 491-497, 2008.

[22] E. C. Deutsch, A. B. Santani, S. L. Perlman et al., "A rapid, noninvasive immunoassay for frataxin: utility in assessment of Friedreich ataxia," Molecular Genetics and Metabolism, vol. 101, no. 2-3, pp. 238-245, 2010.

[23] F. Saccà, G. Puorro, A. Antenora et al., "A combined nucleic acid and protein analysis in Friedreich ataxia: implications for diagnosis, pathogenesis and clinical trial design," PLOS ONE, vol. 6, no. 3, Article ID e17627, 2011.

[24] F. Saccà, A. Marsili, G. Puorro et al., "Clinical use of frataxin measurement in a patient with a novel deletion in the FXN gene," Journal of Neurology, vol. 260, no. 4, pp. 1116-1121, 2013.

[25] M. Naseroleslami, K. Parivar, S. Sanjarian, and E. Khalili, "Investigation of Exon 1 in FXN gene in patients with clinical symptomatic of Friedreich ataxia," Qom University of Medical Sciences Journal, vol. 6, no. 4, pp. 1-7, 2013.

[26] M. L. McCormack, R. P. Guttmann, M. Schumann et al., "Frataxin point mutations in two patients with Friedreich's ataxia and unusual clinical features," Journal of Neurology Neurosurgery and Psychiatry, vol. 68, no. 5, pp. 661-664, 2000.

[27] S. D. Spacey, B. I. Szczygielski, S. P. Young, J. Hukin, K. Selby, and T. P. Snutch, "Malaysian siblings with Friedreich ataxia and chorea: a novel deletion in the frataxin gene," Canadian Journal of Neurological Sciences, vol. 31, no. 3, pp. 383-386, 2004.

[28] M. V. Evans-Galea, L. A. Corben, J. Hasell et al., "A novel deletion-insertion mutation identified in exon 3 of FXN in two siblings with a severe Friedreich ataxia phenotype," Neurogenetics, vol. 12, no. 4, pp. 307-313, 2011.

[29] A. M. W. Van den Ouweland, R. van Minkelen, G. M. Bolman et al., "Complete FXN deletion in a patient with FRDA," Genetic Testing and Molecular Biomarkers, vol. 16, pp. 1015-1018, 2012.

[30] I. Singh, M. Faruq, O. Mukherjee et al., "North and South Indian populations share a common ancestral origin of Friedreich's ataxia but vary in age of GAA repeat expansion," Annals of Human Genetics, vol. 74, no. 3, pp. 202-210, 2010. 

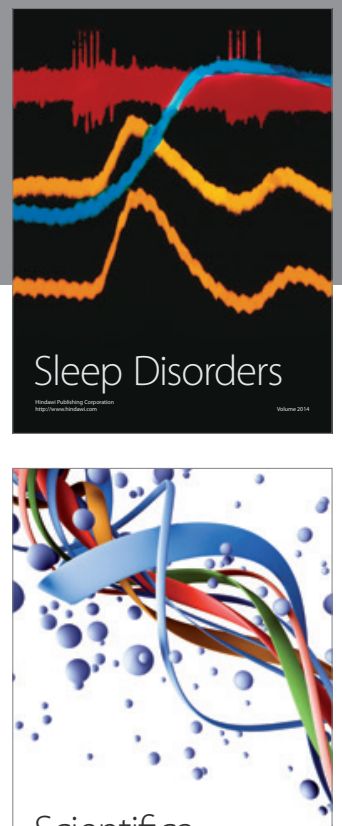

Scientifica
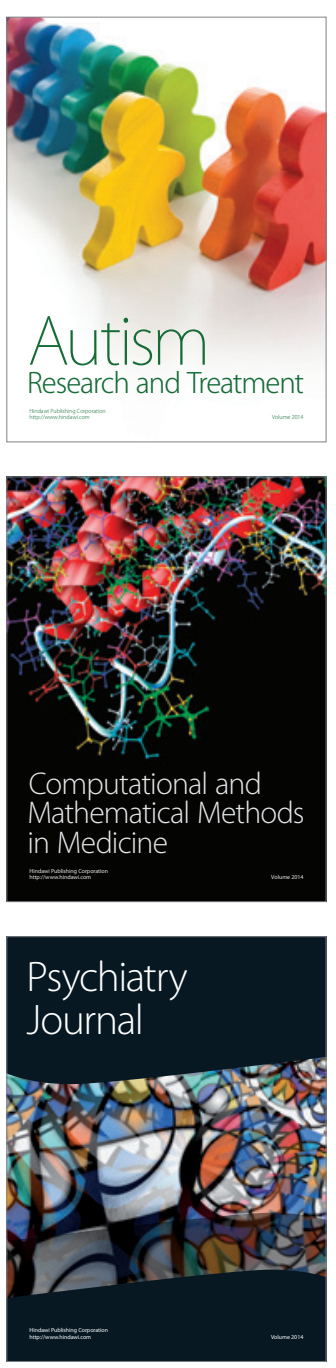
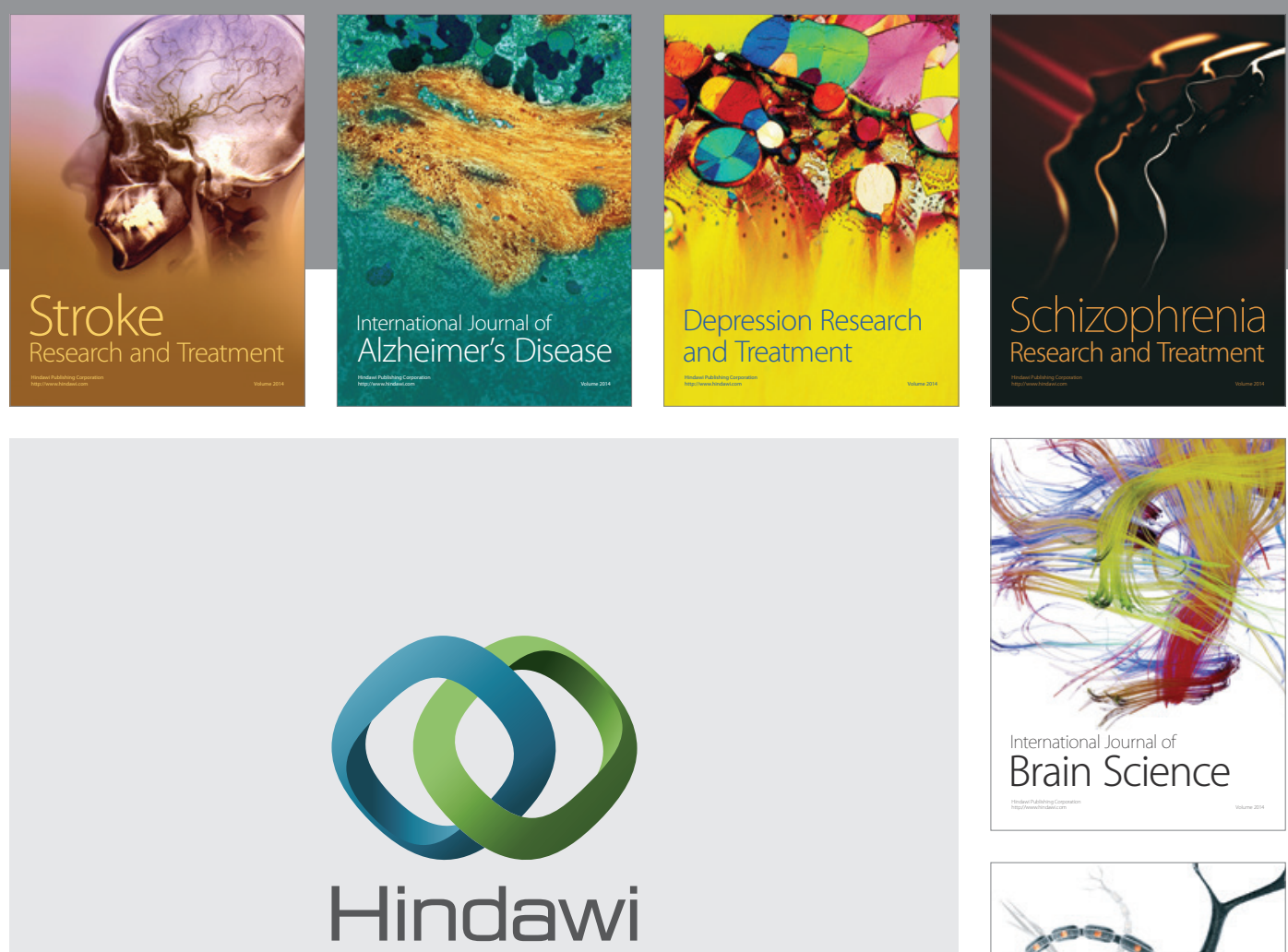

Submit your manuscripts at

http://www.hindawi.com
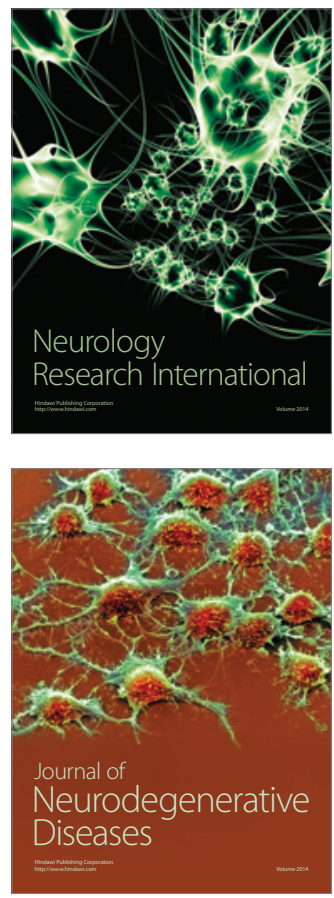

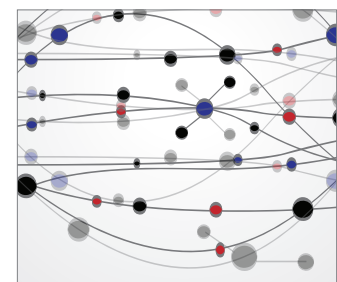

The Scientific World Journal
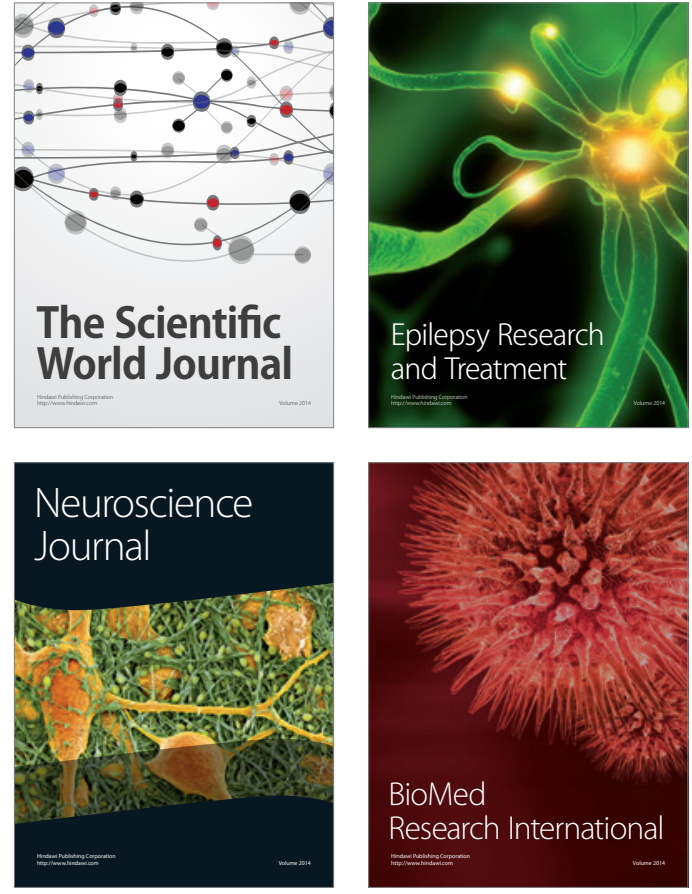

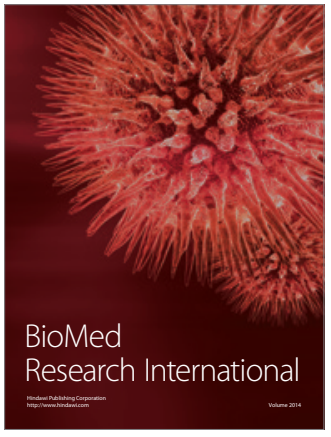

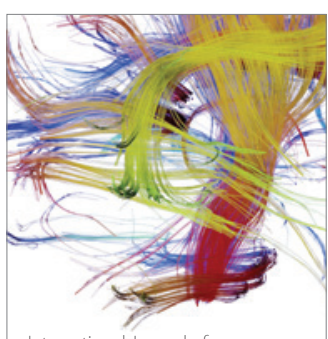

Brain Science

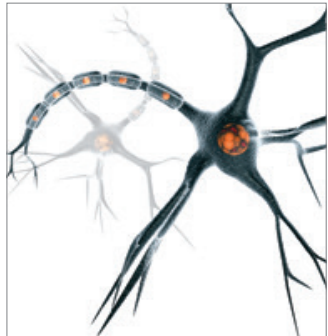

Neural Plasticity
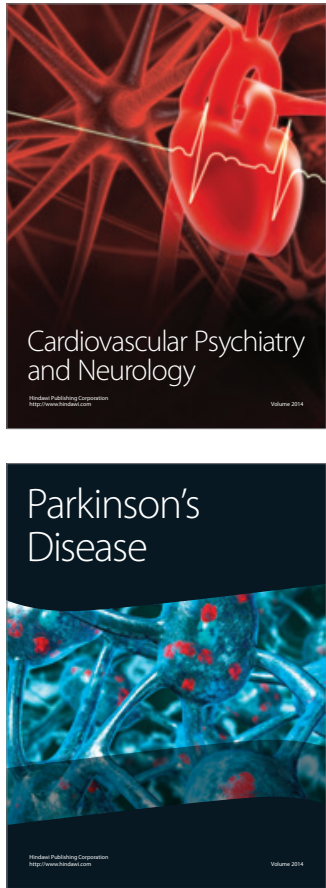